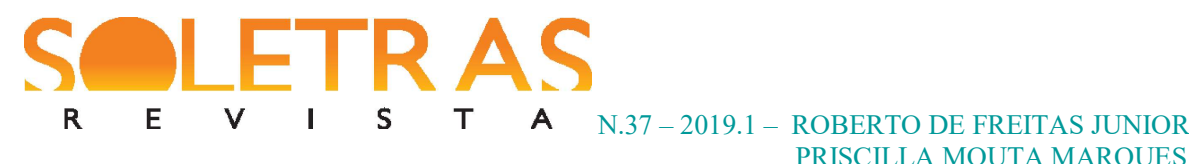

PRISCILLA MOUTA MARQUES

\title{
Sobre links e herança construcional: uma revisão à luz da interrelação entre as construções núcleo-complemento, transitiva básica e monoargumental inacusativa
}

Roberto de Freitas Junior ${ }^{1}$ Priscilla Mouta Marques ${ }^{2}$

Resumo: Este artigo tem como objetivo apresentar uma breve discussão sobre as noções de links e herança apresentadas no trabalho clássico de Goldberg (1995) e no trabalho de Diessel (2015) e analisar a interconectividade existente entre três construções altamente esquemáticas: a construção núcleo-completo (CNC), a construção transitiva básica (CTB) e a construção monoargumental inacusativa (CMI). Pautamo-nos, para este fim, no arcabouço teórico da Linguística Funcional Centrada no Uso (LFCU), segundo o qual a língua é concebida como uma rede de construções, ou seja, um inventário estruturado de pareamentos forma-sentido. A análise aqui desenvolvida aponta para o compartilhamento de propriedades formais e semânticas/funcionais das construções supracitadas: todas as três construções, por exemplo, apresentam a configuração verbo + sintagma nominal com caráter menos agentivo (sendo esta configuração uma subparte da CTB) e caracterizamse pela forte tendência de apresentarem alto grau de novidade e/ou saliência da informação, assumindo, portanto, um papel mais focal.

Palavras-chave: Rede construcional. Links. Construções de estrutura argumental.

\section{Introdução}

A abordagem construcionista da gramática (GOLDBERG, 1995; 2006; CROFT, 2001; BYBEE, 2010), na vertente em que se conforma aos pressupostos teórico-metodológicos dos Modelos Baseados no Uso (BARLOW \& KEMMER, 2000), prevê que as estruturas linguísticas, reconhecidas como construções gramaticais, sejam fruto de cristalizações geradas a partir do uso da língua (BYBEE, 2007). Sob essa perspectiva, a gramática de uma língua é entendida como uma rede de construções, cujos links podem ser estabelecidos pelo compartilhamento de propriedades entre elas - o que se configuraria na defesa de que essas relações podem ser oriundas de heranças entre construções particulares.

\footnotetext{
${ }^{1}$ Graduado em Português/Inglês pela Universidade Federal do Rio de Janeiro (1999) com especialização em Língua Inglesa pela Puc-Rio (2001), mestrado em Linguística pela Universidade Federal do Rio de Janeiro (2006) e doutorado em Linguística pela Universidade Federal do Rio de Janeiro (2011). Professor Adjunto de Estudos Linguísticos do Departamento de Letras-Libras/UFRJ e do Programa de Pós-graduação em Linguística da UFRJ. Membro do grupo de pesquisa Discurso \& Gramática (D\&G/UFRJ) e coordenador do Núcleo de Estudos sobre Interlíngua e Surdez (NEIS/UFRJ).

${ }^{2}$ Professora Adjunta de Linguística da Faculdade de Letras da Universidade Federal do Rio de Janeiro. Docente do Programa de Pós-Graduação em Linguística da mesma instituição. Pesquisadora do Grupo de Estudos Discurso \& Gramática.
} 


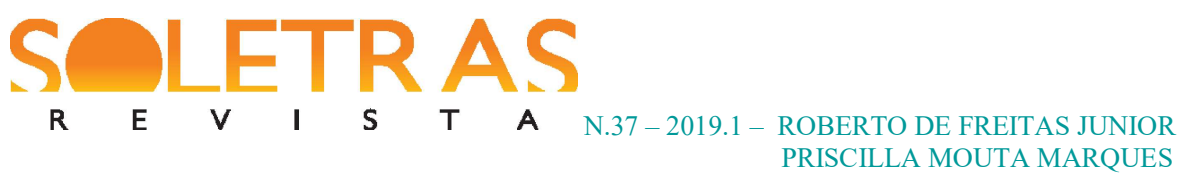

Sendo assim, neste artigo, procuramos abarcar questões relacionadas às noções de links e herança, a partir da análise de algumas construções de estrutura argumental do Português do Brasil (PB). Na primeira seção, intitulada Links e herança: uma revisão, apresentamos as propostas de Goldberg (1995) e Diessel (2015) para o tratamento da interrelação entre construções na rede - a configuração do construct-i-con - e uma breve discussão acerca de tais propostas. $\mathrm{Na}$ segunda seção, investigamos os links entre as construções núcleo-complemento, transitiva básica e monoargumental inacusativa, construções estas hierarquicamente mais altas na rede. Destacamos que, embora sejam apresentados na seção 1 , por fidelidade às propostas dos autores supracitados e consequente comparação entre elas, links que podem ser depreendidos em níveis mais baixos na rede, nos ateremos à ilustração de propriedades compartilhadas entre construções mais abstratas, sem perder de vista, porém, o postulado de emergência da gramática. Por fim, apontamos algumas considerações finais.

\section{Links e Herança: uma revisão}

A arquitetura da linguagem, na perspectiva da Linguística Cognitiva, é tida por uma rede de construções relacionadas, de formação semelhante à formação do conhecimento como um todo: via associações simbólicas regidas por princípios cognitivos gerais. O conceito de rede construcional e suas relações consiste, nesse sentido, essencialmente, na ideia de que tudo na língua pode ser descrito em termos de nós e tipos de relação/herança, tal como apresentado em Hudson (2007).

Assim sendo, se a gramática, como componente cognitivo, consiste, fundamentalmente, em sinais, a tradicional distinção gramática/léxico torna-se dispendiosa, para não dizer equivocada. Em outras palavras, tal concepção de gramática não diferencia a natureza constitutiva de itens lexicais e a de itens gramaticais: são todos signos, ou seja, pareamentos de forma e sentido. Daí se origina a hipótese de que a língua seja uma rede de signos relacionados, organizados em um continuum de natureza [+/- lexical/gramatical] ou [+/- referencial/procedural]. 


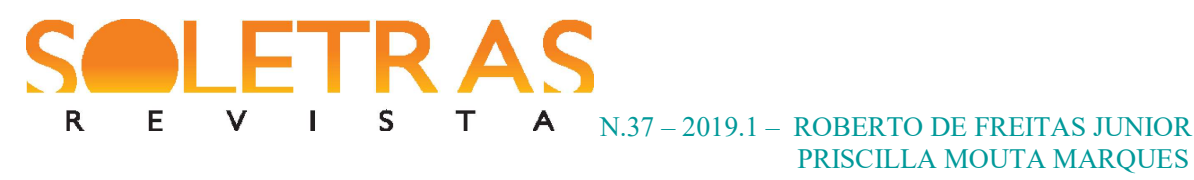

Segundo Diessel (2015), as construções seriam sinais linguísticos de diferentes graus de complexidade, que combinam um padrão estrutural particular com uma função ou significado também particular. As construções estariam relacionadas entre si, seja por conta de graus de parentescos estabelecidos no nível do sentido ou no da forma. A figura abaixo, extraída do trabalho do autor, exemplifica como os itens lexicais podem manter entre si algum grau de ligação de sentido:

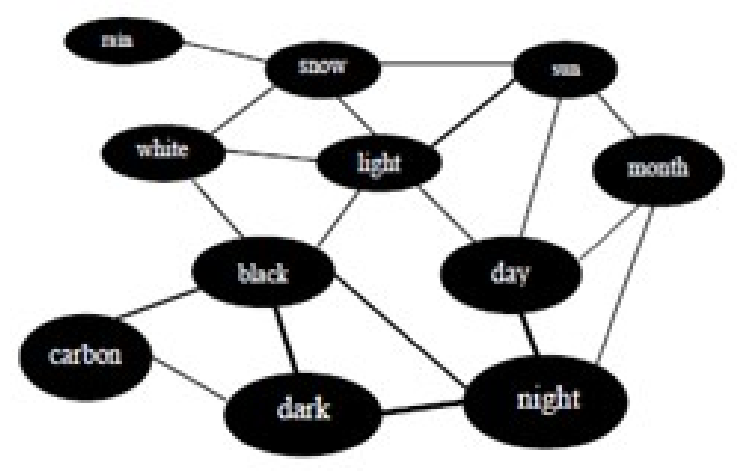

Figura 1: Rede lexical (extraída de Diessel, 2015).

A grande contribuição dessa proposta consiste no confronto do pressuposto construcional de que toda a gramática é uma rede de associações simbólicas, de natureza [+/lexical/gramatical] com o de teorias formais, de orientação gerativista, que estabelece distinção entre uma gramática nuclear (core grammar) e uma gramática periférica. Esta, a gramática periférica, seria adquirida de modo independente do que estaria disponível a priori em termos de cognição e linguagem.

Assim, a aquisição de expressões idiomáticas, por exemplo, não aconteceria pelo mesmo processo de aquisição de uma dada estrutura argumental. Isso significa dizer que expressões idiomáticas seriam "aprendidas" de modo diferenciado e a posteriori, em relação às estruturas argumentais. Reside aí uma diferença central que distingue as duas visões - a construcional e a gerativista -, já que para a abordagem construcional, tanto estruturas argumentais, itens lexicais e mesmo expressões idiomáticas seriam pareamentos de formasentido, conectados em uma única rede de construções: a própria gramática. 


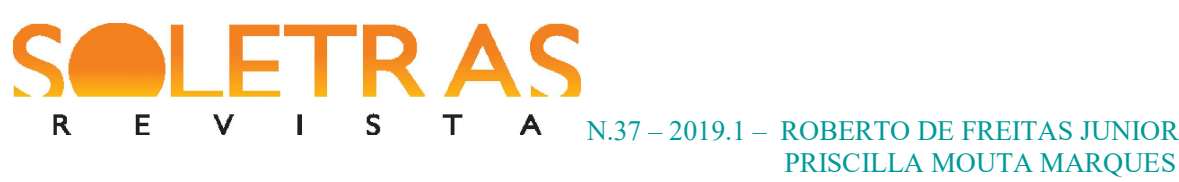

A noção de signo, assim, é alavancada em relação à versão tradicional, de orientação lexical, abrangendo construções esquemáticas, gramaticais, incluindo-se, aqui, as de estrutura argumental. Como já mencionado anteriormente, seriam todas, estas e aquelas, essencialmente, sinais, compostos binários de forma-função, conectados em uma grande rede simbólica, formada a partir da associação de suas características de forma e/ou função.

O trabalho de Goldberg $(1995)^{3}$ destaca o papel das construções de estrutura argumental no inglês, por se constituírem em pareamentos forma-sentido específicos, tal como qualquer item lexical, ou expressão idiomática. Destaca, ainda, como tais construções de estrutura argumental encontram-se conectadas, seja no nível do sentido, seja no nível formal, por relações de diferentes naturezas, também tal como qualquer item lexical, ou expressão idiomática.

Ao colocar no mesmo plano construções de estruturas argumentais, lexicais e idiomatismos, o trabalho estabelece uma perspectiva de gramática não condizente com a dicotomia gramática central/gramática periférica. Por conseguinte, retifica a noção léxico/gramática como categorias discretas, estabelecendo a noção de contínuo léxico/gramática, ao longo do qual as construções se organizam entre si por maior ou menor proximidade, em função de suas características formais e/ou semântico/funcionais.

Assim, as construções estariam organizadas no construct-i-con por tipos de relações diferenciadas, resumidas, segundo a autora, em dois grandes grupos, ou tipos de links: os relacionais e os de herança.

São tratados como links relacionais aqueles que identificam as diferentes formas como as construções se relacionam entre si em termos de forma e/ou sentido. A autora, em suma, apresenta sua visão, defendendo que os links relacionais podem acontecer por polissemia, por extensão metafórica, de subparte e de instanciação. Resumidamente, os links apresentados em Goldberg (1995) podem ser apresentados da seguinte forma:

a. links polissêmicos: apontariam para um determinado número de sentidos conceptualmente relacionados e ligados a uma forma/semântica central, como exemplificado nas possibilidades construcionais da construção ditransitiva prototípica do Inglês, em que a noção de

\footnotetext{
${ }^{3}$ Vale citar que Goldberg (1995) não apresenta um modelo representativo da Gramática de Construções Baseada no Uso, dada a característica abstracionista deste trabalho especificamente, sendo, portanto, menos sujeita ao papel do uso e da experiência.
} 
intencionalidade fica preservada (She cooked him dinner/ She enabled him a 6-month sabbatical);

b. links por extensão metafórica: existiriam entre os domínios fonte e alvo, como ocorre nas construções de movimento causado e nas resultativas do Inglês, em que na primeira a noção de movimento é de natureza locativa, enquanto na segunda é de natureza resultativa (He pushed her there/ He pushed her clear);

c. links de subparte: indicariam relações metonímicas entre construções, já que algum aspecto de uma construção poderia ser identificado na outra, como a construção intransitiva de movimento do Inglês, que guarda o traço de deslocamento do elemento SUJ, típica da de movimento causado (He pushed her into the room > The fly buzzed into the room) e

d. links de instanciação: representariam a relação existente entre duas construções, na qual uma seria uma exemplificação da outra, como na relação existente entre os itens (veículos $>$ carro $>$ Sedan);

Os links de herança de Goldberg (1995), por outro lado, refletiriam as múltiplas informações construcionais advindas de diferentes esquemas presentes em determinada construção. Os links de herança representariam mais a rede taxonômica de construções, os diferentes nós, hierarquicamente organizados na rede, presentes, possivelmente numa gama de amálgamas construcionais, em um dado constructo ou construção.

A Linguística Funcional Centrada no Uso (LFCU), modelo aqui apresentado, também abandona a divisão rígida entre léxico e gramática e o pressuposto de um componente inato específico para a aquisição da linguagem. Assim o faz em favor de um modelo de rede no qual todos os elementos são adquiridos pela experiência e são conectados a partir de características específicas de sua forma ou de sua função.

De acordo com Diessel (2015), o que todos os modelos de rede têm em comum - e aqui incluímos a LFCU - é a centralidade do processamento de dados reais e da aprendizagem pela experiência. Os modelos de rede são, portanto, modelos baseados no uso, por definiç̧ão. Apresentamos, assim, sua alternativa de classificação de links para a tradicional classificação de Goldberg (1995), por se tratar este não de um trabalho de orientação abstracionista, mas baseado no uso. Diessel (2015) considera quatro tipos diferenciados de organização das construções na rede que, de modo bastante econômico, refletem a abordagem gramatical 


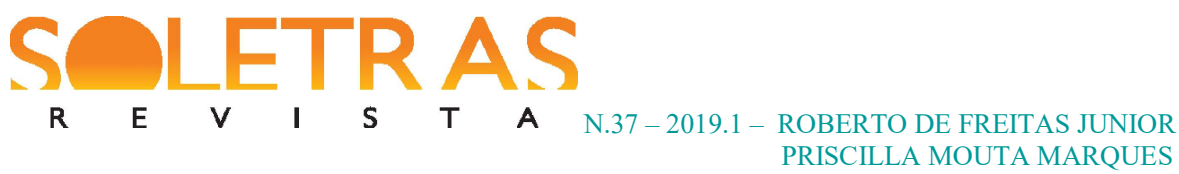

experiencialista - levando em conta fatores relacionados ao processamento, à frequência de uso e à aquisição da linguagem. Segundo o autor, uma rede construcional apresentaria relações entre construções em diferentes níveis de abstração (links taxonômicos), relações entre construções no mesmo nível de abstração (links horizontais), relações entre construções e categorias sintáticas (links sintáticos) e relações entre construções e expressões lexicais (links lexicais). Vejamos:

a. links taxonômicos: dizem respeito à organização hierárquica das construções, quando organizadas entre si a partir de maior ou menor grau de abstração. Em outras palavras, se as construções são representações esquemáticas da estrutura lingüística, elas são instanciadas em enunciados concretos e surgem como generalizações, em um processo de esquematização, a partir da experiência, desde a infância, já no curso da aquisição da linguagem. No curso da aquisição, as crianças aprendem uma hierarquia de padrões gramaticais $+/$ - abstratos. $\mathrm{O}$ esquema da sequência, retirado do trabalho do autor, exemplifica, seja via sentido top-down, seja via sentido bottom-up, a relação taxonômica existente entre construções mais abstratas e suas possíveis instanciações:

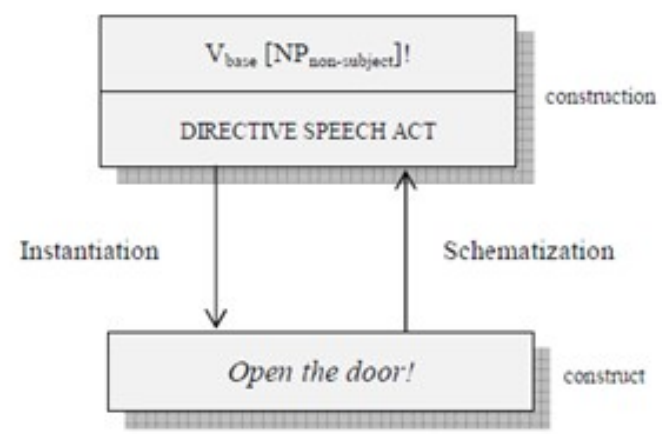

Figura 2: Links taxonômicos (DIESSEL, 2015).

b. links horizontais: referem-se às relações entre construções no mesmo nível de abstração, sejam elas esquemáticas ou lexicalmente preenchidas. Novamente, em termos de aquisição e processamento, pesquisas mostram que o desenvolvimento gramatical é crucialmente influenciado por semelhanças estruturais e semânticas entre construções, uma evidência para a natureza desse tipo de relação construcional. 
c. links sintáticos: apontam para a relação existente entre construções e categorias sintáticas. Uma abordagem baseada no uso prevê a emergência das categorias sintáticas a partir da experiência dos usuários da língua com construções, desde a aquisição. Assim, construções, e não categorias e relações, são as unidades básicas e primitivas da representação sintática (Croft 2001). A relação entre construções e categorias é semelhante àquela entre construções em diferentes níveis de abstração, que a partir da experiência, ou seja, pela via bottom-up, levam à formação de categorias emergentes, adquiridas na infância e ajustadas ao longo das vida. O esquema abaixo, também retirado do trabalho de Diessel (2015), exemplifica, a relação construções/categorias sintáticas, apresentada pelo autor:

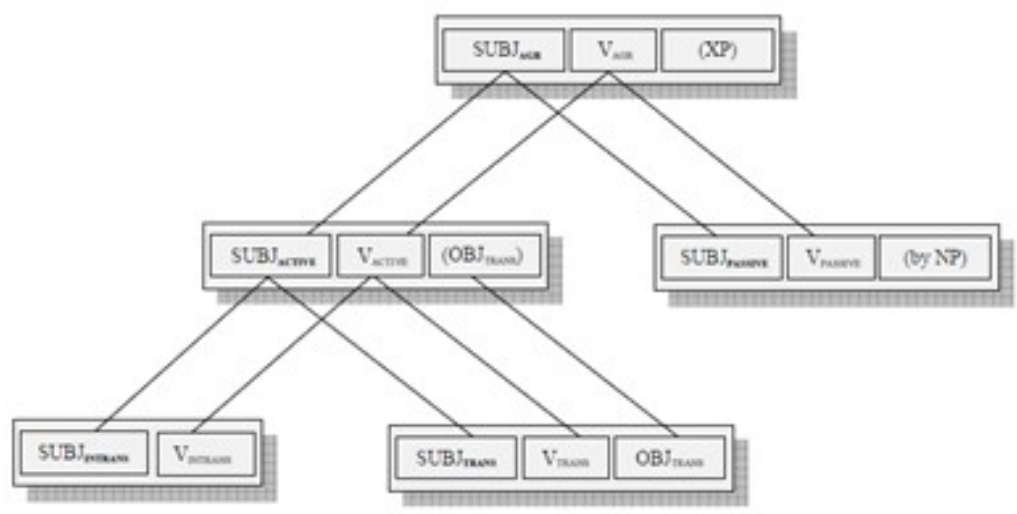

Figura 3: Links sintáticos (DIESSEL, 2015).

d. links lexicais: refletem ligações associativas entre construções (esquemáticas) e expressões lexicais (concretas). Na abordagem baseada no uso, a estrutura linguística é fundamentada na experiência com expressões lexicais concretas e algumas construções podem estar mais frequentemente associadas a determinadas palavras. Stefanowitsch e Gries (2003) mostram, por exemplo, que certos lexemas estão mais (ou menos) estatisticamente propensos a emergirem em uma dada construção. Diessel (2015) exemplifica tal associação, via uso do verbo togive(dar), em inglês, mais associado à construção ditransitiva e o verbo tobring(trazer), mais associado à construção dativa: 


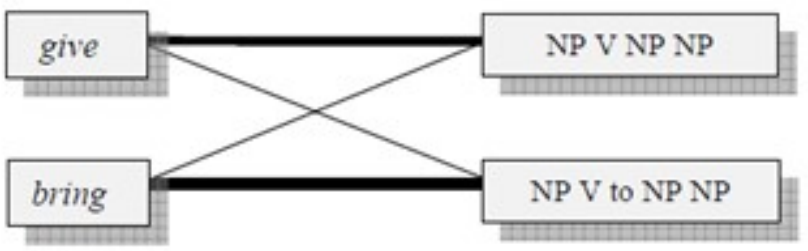

Figura 4: Links lexicais (DIESSEL, 2015).

Apresentada essa breve revisão, a título de exemplificação sobre links e herança construcional, passamos a discutir, na sequência, as múltiplas relações de forma e sentido entre construções do PB.

Para tal feito, propomos discutir a interrelação entre a Construção NúcleoComplemento (CNC), referida em Kay \& Fillmore (1999), a Construção Transitiva Básica $(\mathrm{CTB})^{4}$ e a Construção Monoargumental Inacusativa (CMI) - considerando, neste caso, a inacusatividade nos termos de Burzio (1986) -, que englobaria orações monoargumentais ativas e passivas com menor papel de agentividade atribuído ao seu $\mathrm{SN}$ e a marcação não categórica de Caso Nominativo.

\section{Discutindo Links e Herança entre a Construções Núcleo-Complemento, Construção Transitiva Básica e a Construção Monoargumental Inacusativa}

A interrelação CTB - CNC - CMI consistiria, em primeiro lugar, na possibilidade de a CNC - construção do tipo [Núcleo SPrep/SN-agt] - ser herdada tanto pela CTB - do tipo [SN [V SN]]) - como pela CMI - do tipo [VSN-agt]. Em outras palavras, defendemos que propriedades concernentes à $\mathrm{CNC}$, seja no nível da forma, seja no nível do sentido,seriam verificadas em orações SVC e em orações VS em que o sujeito é [- agentivo]. O quadro a seguir procura mostrar as propriedades de cada uma das construções estudadas:

\footnotetext{
${ }^{4}$ A CTB pode ser representada por construções de duas naturezas. A primeira, tratada no presente artigo, prevê a atividade de transferência entre SNs SUJ agentivos e SNs OBJ Tema/Paciente (afetado); a segunda prevê a relação de transferência entre SNs SUJ Experienciadores e Complementos verbais.
} 


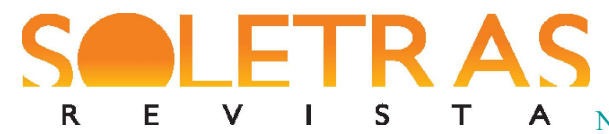

$\mathbf{R}$

$\mathbf{S}$

N.37 - 2019.1 - ROBERTO DE FREITAS JUNIOR

\begin{tabular}{|c|c|c|c|}
\hline $\begin{array}{c}\text { Construção } \\
\text { Núcleo - }\end{array}$ & $\mathrm{CNC}$ & $\begin{array}{c}\text { CNCn - Núcleo N - }\left[\mathrm{N}_{\mathrm{NOME}}\right. \\
\text { SPrep }]\end{array}$ & $\begin{array}{c}\text { Necessidade de trabalho } \\
\text { Ocorreu um acidente }\end{array}$ \\
\hline Complemento & & $\begin{array}{c}\text { CNCv - Núcleo V - } \\
{\left[\mathrm{N}_{\text {VERB }} \text { SPrep/SN-agt }\right]}\end{array}$ & \\
\hline $\begin{array}{c}\text { Construção } \\
\text { Transitiva } \\
\text { Básica }\end{array}$ & CTB & [SN [V SN-agt]] & João comeu a maçã \\
\hline $\begin{array}{c}\text { Construção } \\
\text { Monoargumental } \\
\text { Inacusativa }\end{array}$ & CMI & [VSN-agt] & Apareceu a Margarida \\
\hline
\end{tabular}

Para tratar das relações de herança dos tipos construcionais demonstrados na tabela anterior, vamos começar analisando a construção CNC. Em termos gerais, entendemos que tal construção abarcaria duas relações monoargumentais de naturezas distintas: uma nominal $(\mathrm{CNCn})$ e outra verbal (CNCv), como propomos na representação seguinte:

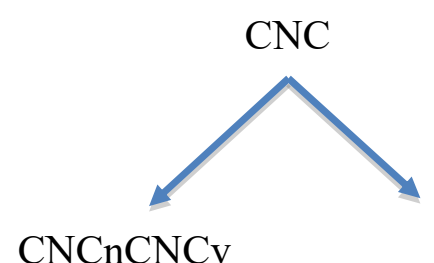

O status construcional de CNC fica evidenciado, na medida em que verificamos, tanto no nível da forma, quanto no nível do sentido, características específicas dessa construção. No nível da forma, a CNC apresentaria a configuração [Núcleo - Complemento], enquanto, no nível do sentido, apresentaria restrições semânticas a respeito do elemento que pode figurar no slot "complemento", que deverá apresentar característica de menor agentividade. 
Assim, por consequência, entendemos que CNC abarcaria formações do tipo [Núcleo Nominal - Complemento], enquanto a $\mathrm{CNCv}$ englobaria outras do tipo [Núcleo Verbal Complemento], apresentando, ambas, para além de suas características formais, características semânticas condizentes com a CNC.

Se, no nível da forma, a CNCn apresentaria uma estrutura do tipo [Núcleo nominal Complemento], no nível do sentido apresentaria uma relação semântica entre o núcleo e seu argumento que aponta este como objeto deslocado ou afetado pelo conteúdo lexical do Núcleo nominal, tal como é possível observar abaixo:

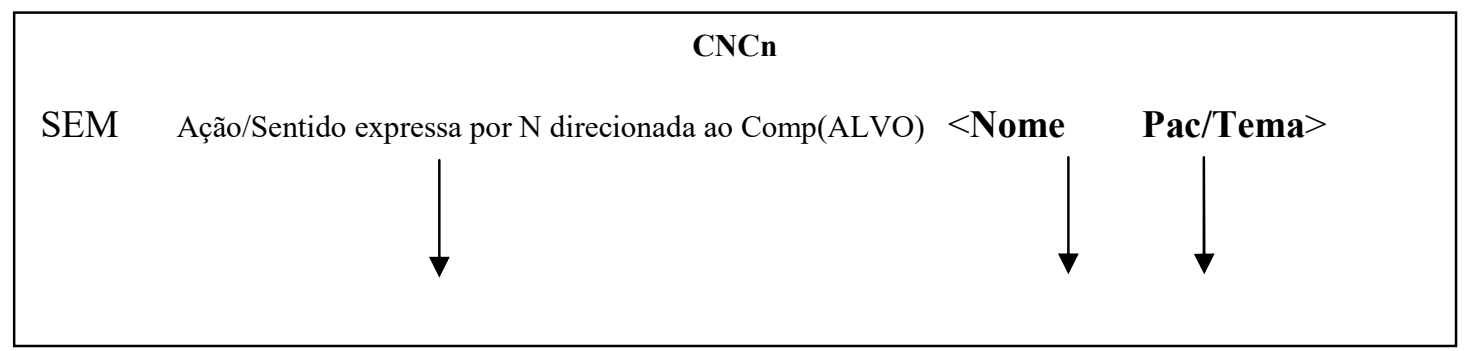

Tal construção instanciaria, por exemplo, microconstruções como [NECESSIDADE de SN], [RESPEITO por SN], [CONSTRUÇÃO de SN].

Por seu turno, a CNCv, em termos formais, também apresenta um item lexical nuclear, neste caso, de natureza verbal, e um SN ou SPrep e pode ser representada pelo esquema $\left[\mathrm{N}_{\mathrm{VERB}} \mathrm{SN} / \mathrm{SPrep}\right]^{5}$. A construção restringe semanticamente seu argumento como objeto afetado, no caso, pela ação expressa pelo núcleo verbal, como vemos abaixo:

CNCv

SEM Ação/Sentido expressa por V direcionada ao Comp(ALVO) $<$ Verbo

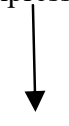

Pac/Tema>
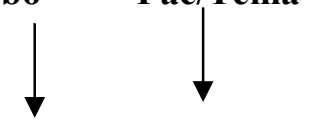

\footnotetext{
${ }^{5}$ Neste trabalho focalizamos apenas a construção $\mathrm{CNCV}$ formada por um $\mathrm{N}_{\mathrm{VERB}}$ e um complemento SN.
} 


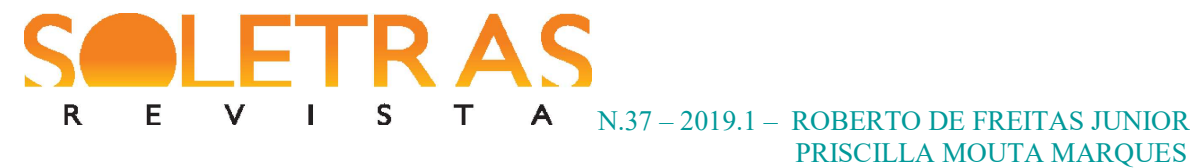

Trata-se, a CNCv, assim, de uma construção altamente esquemática, também passível de ser representada como [V SN]. Em termos de sentido, portanto, temos um item verbal ligado a um SN de natureza bem definida, na medida em que apresenta traços semânticos [Agente] e [-Volitivo], o que sugere, como visto, que o item seja interpretado como elemento não executor da ação verbal e talvez mais suscetível a mudanças oriundas da ação expressa pelo verbo, desempenhando papel temático TEMA/PACIENTE. Conforme Cançado (2005), o papel temático TEMA encobre entidades que sofrem deslocamento proveniente da ação verbal, enquanto o papel temático PACIENTE refere-se a entidades que sofrem efeito de alguma ação, havendo mudança de estado, tal como parece ocorrer com o único argumento de CNCv.

$\mathrm{Na}$ verdade, o que parece estar em jogo na $\mathrm{CNC}$, tanto na de natureza verbal, quanto na de nominal, é o fato de, no nível do sentido, ambas apresentarem a semântica de 'Ação/Sentido expressa por $N$ / $V$ direcionada ao Comp (ALVO)', o que pode ser identificado nos exemplos (1) e (2), abaixo, constructos instanciados, respectivamente, pela CNCN e pela CNCV:

(1) João viu a construção do prédio (TEMA)

(2) Quebrou o vaso (PACIENTE)

$\mathrm{O}$ ponto que queremos aqui destacar está relacionado à $\mathrm{CNCV}$ e diz respeito especificamente à possibilidade de propriedades de tal construção serem compartilhadas por outras do tipo CTB e CMI. Em suma, o que se pretende discutir é a possibilidade de afirmarmos que a $\mathrm{CNCv}$, uma construção de alto grau de esquematicidade, manteria relação de herança construcional (GOLDBERG, 1995) tanto com a CTB, quanto com a CMI, na medida em que o comportamento semântico do SN complemento da oração transitiva prototípica e o do único argumento da oração inacusativa são coincidentes, por apresentarem, ambos, características semânticas de baixa agentividade. Isso, então, revela o compartilhamento de propriedades da $\mathrm{CNCv}$ por essas construções, evidenciando uma relação apriorística de herança construcional: 


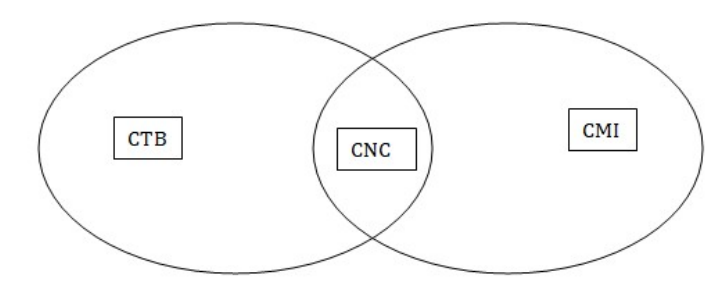

Resumidamente, se o argumento da $\mathrm{CNCv}$ não detém caráter de agentividade em relação ao evento expresso pelo verbo, uma análise atenta nos mostra que tal fato também parece ocorrer na relação entre o item verbal e o argumento interno das construções inacusativas, ativas e passivas, nas quais ficam resguardados os traços semânticos [-Agente] e [-Volitivo] do SN (por exemplo: Ocorreu um acidente, Apareceu a Margarida, A porta abriu). Da mesma forma, a CTB revela esta condição, já que um SN [+agt] afeta, via ação expressa pelo item verbal, o $\mathrm{SN}[+$ pac $]$.

O que estamos chamando de CTB são padrões em que formalmente há presença de um SN SUJ, de um verbo e de um SN complemento. Semanticamente temos, em termos prototípicos, um Sujeito [+agt], um verbo de maior grau de transitividade (HOPPER \& THOMPSON, 1980) e um complemento afetado, conforme verificamos na representação $\left[\mathrm{SUJagt}+\left[\mathrm{V}_{\text {TRANS }}+\mathrm{SN}\right.\right.$ Comp $\left.]\right]$, em que o complexo [V Comp] corresponderia à própria $\mathrm{CNCv}$, como verificamos nos exemplos $(3-5)$ a seguir:

(3) João comeu a maçã.

(4) ?A máquina comeu a maçã.

(5) ??A pedra comeu a maçã.

Os exemplos $(3-5)$ parecem demonstrar não só que o sentido construcional da CTB reflete transferência da ação do SN SUJ ao SN OBJ, afetando-o, mas também que há a existência de restrições semânticas concernentes ao SN SUJ, posto que ele apresentará papel temático prototípico de [+agt].Em outras palavras, em um contexto de uso a partir do qual pudessem ser atribuídos os traços [+Agentividade] e [+Animacidade] a nomes como $<$ máquina $>$ e $<$ pedra $>$, (4) e (5) seriam processados, por coerção, como constructos da CTB. 
Entendendo, então, que a $\mathrm{CNCv}$ poderia ser também caracterizada pelo esquema [VSN-AGT] e que estaria refletida em complexos de diferentes naturezas, transitivas e inacusativas, como as apresentadas a seguir:

[CORTAR PAPEL]

\section{[ACONTECER UM ACIDENTE]}

\section{[SER CORTADO O PAPEL]}

Sugerimos que haja uma relação do tipo de subparte entre a CNCv, a CTB e a CMI, tanto no nível da forma, quanto no do sentido, ou seja, as especificações sintático-semânticas da CTB e CMI são subpartes das especificações sintático-semânticas da CNCv.

Assim, a construção de base [VSN-AGT] instancia diferentes constructos do PB, como podemos verificar nos exemplos abaixo:

(6) João cortou o papel.

(7) Aconteceu um acidente com o papel.

(8) Foi cortado o papel.

O ponto dessa discussão consiste na investigação das características formais e funcionais de [V SN-AGT] herdadas e compartilhadas por CTB e CMI, já que, ao compararmos a estrutura argumental de construções transitivas e inacusativas, verificamos semelhanças entre elas.

No presente artigo ressaltamos que em casos como [SER CORTADO O PAPEL], exemplo da CMI, assim como na construção inacusativa lexical ${ }^{6}$, temos um SN [+PACIENTE], ou seja, não detentor do caráter de agentividade. De fato, se o argumento sujeito, [+AGENTE], da oração ativa original, emergir no contexto de uso, isto se dará sob a forma de um sintagma preposicional, tradicionalmente, o agente da passiva, um termo "acessório".

\footnotetext{
${ }^{6}$ Entendemos que a Construção Inacusativa Lexical é aquela composta por um item verbal acompanhada de um $\mathrm{SN}_{- \text {agt }}$, análoga à construção inacusativa passiva, de ordem sintática (por exemplo: APARECER SN / SER VISTO SN). 
É importante também apontar que, diferentemente do que ocorre na construção base [V SN-AGT], há outras relações semânticas nas construções monoargumentais de natureza inergativa (Cinerg), nas quais temos um SN [+Agente] e [+Volitivo], como representado a seguir: [SN+AGT V].

Novamente, é possível traçar as características de forma e sentido que a caracterizariam como uma construção diferenciada da construção [V $\left.\mathbf{S N}_{-\mathbf{A G T}}\right]$. Se, por um lado, no nível da forma, temos uma construção também monoargumental, por outro, no nível do sentido, temos um fator importante que as diferencia: o papel de agentividade do SN em relação ao evento, como verificado nas sequências abaixo:

\section{[O HOMEM TELEFONOU] [O HOMEM TRABALHOU]}

Diante do apresentado, parece inevitável uma discussão sobre as características semânticas da $\mathrm{CNCv}$ - V SN-AGT] - e questões relacionadas à informatividade. Diferentes estudos sobre a ordem VS (verbo-sujeito) no $\mathrm{PB}$ associam fatores informacionais à emergência de constructos de SNs monoargumentais pospostos (cf.: Pezatti (1994), Naro e Votre (1999), Spano (2002 e 2008), Freitas (2006 e 2011), Marques (2012)). Mesmo na atual sincronia, na qual tal ordem não é favorecida, encontramos instâncias dessa ordenação, na voz passiva e com itens verbais, particularmente, embora não exclusivamente, inacusativos.

Seguindo uma abordagem construcional, estudos desenvolvidos no projeto Investigando $[(X)[V S N]]_{F O C}$ no PB: uma construção focal em rede?, pelo grupo de estudos Discurso \& Gramática (D\&G/UFRJ), têm por objetivo a análise e descrição sincrônicas de padrões construcionais relacionados ao esquema monoargumental $[(\mathrm{X})[\mathrm{VSN}]]_{\mathrm{FOC}}{ }^{7}$. Entre suas propostas está o mapeamento da rede, na qual tal construção figuraria como nó central, e que vislumbre as múltiplas relações de forma e sentido de seus pareamentos intermediários. Assim, procura caracterizar o esquema construcional supracitado em termos de forma e sentido, buscando verificar as características formais de seus subesquemas e relacionar a questão da informatividade, em particular, no que tange à discussão de foco informacional, para explicação das características no nível da função/sentido do pareamento.

\footnotetext{
${ }^{7} \mathrm{O}$ elemento $(\mathrm{X})$ aqui considerado tende a ser um SADV ou um SPrep de natureza adverbial com caráter coesivo. 


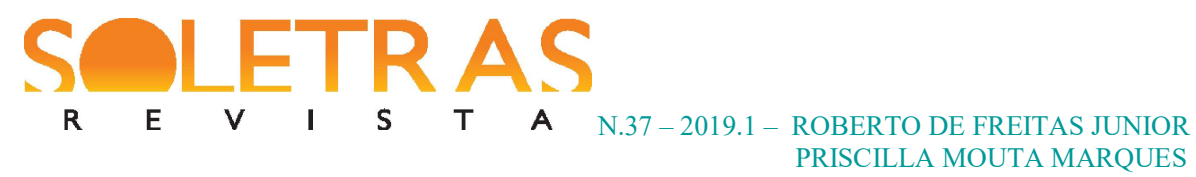

Teríamos, portanto, encabeçados pelo esquema $[(\mathrm{X})[\mathrm{VSN}]]_{\mathrm{FOC}}$, subesquemas que contemplariam types e tokens monoargumentais de natureza ativa e passiva, interligados em rede e funcionando como signos específicos, porém, polissêmicos (Goldberg, 1995 e 2006), sancionados pelo esquema original via nódulos de herança. Portanto, os subesquemas $[(\mathrm{X})[\mathrm{VSN}]] \mathrm{FOC}_{\mathrm{ATV}}$, representação das cláusulas ativas, e [(X)[[VAuxVpp]SN]]FOC ${ }_{\mathrm{PAS}}$, representação das cláusulas passivas, estariam, na rede taxonômica, em nível hierárquico superior a microconstruções que, em termos de sentido, poderiam indicar tendência de focalização do todo sentencial, por perspectivização do evento, ou do $\mathrm{SN}$ em posição pós verbal, seja por apresentação de informação nova, seja por reintrodução (retomada) de um SN dado no nível do discurso.

Dessa forma, o esquema [(X) VSN]FOC estaria, em termos de herança, ligado à construção $\mathrm{CNCv}$ na medida em que apresenta microconstruções monoargumentais, ativas e passivas, com complemento [-agentivo]. Por outro lado, já que apresenta, em termos de sentido, o papel da focalização de SNs e/ou eventos, o esquema também abarcaria instâncias monoargumentais das Construções Inergativas- Cinerg. Isso se dá devido à possibilidade de todo um evento, ou mesmo os SNs [+agt] dessas construções, emergirem no padrão posposto, seguindo o papel da focalização, associado, sincronicamente, à construção.

Destaca-se, aqui, a possibilidade de ocorrência de constructos instanciados pelo esquema [(X) VSN]FOC que apresentam SNs [+agt]. Embora esses casos não sejam prototípicos, eles evidenciam a força pragmático-discursiva de focalização da construção, que, por sua vez, guia o uso e a interpretação de tais constructos, independentemente da grade argumental a que pertence o item verbal em questão.

O esquema a seguir evidencia as relações de herança supracitadas: 


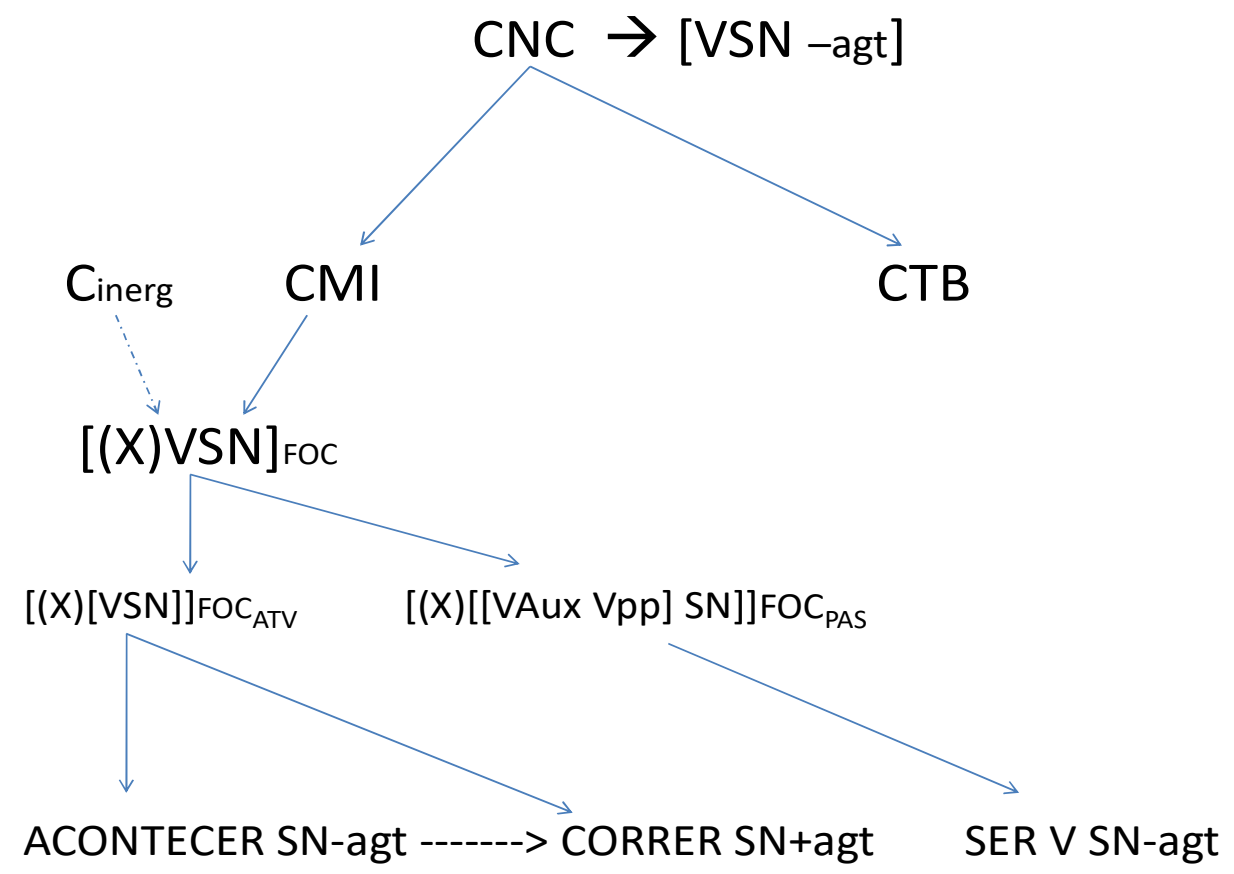

Os exemplos $(9-14)$, retirados do Corpus do Português e do jornal $O$ Globo impresso no período de 2015 - 2017, ilustram tais relações:

(9) O Marlon Brando estava fazendo um filme [...] e eu estava lá. Quis demais conhecê-lo. No mesmo dia, aliás, aconteceu uma história incrível.

(10) Na operação da PF, estão sendo levadas para depor pessoas ligadas às avaliadoras desses fundos, como empresas de auditoria. Se elas não viram o erro, é preciso também investigar as causas

(11) Ao surgir a televisão, em 1950, correu o boato de que não era recomendado assistir aos programas por mais de quinze minutos seguidos.

(12) Correu a negrada toda assuntando a aparição.

(13) [...] uma vez que eu estava em Itanhaém - no dia oito de dezembro e chegaram os umbandistas.

(14) Depois, chegou uma época que eu fiz corpo inteiro, mas eu já estava tão identificada com o público, que ele nem cobrava mais o padrão estético do meu corpo. 
Os dados apresentados revelam o padrão construcional acerca do esquema de focalização aqui defendido. Em termos de forma, constitui-se em um esquema monoargumental, cujo SN tende a ser [-agt], fato que evidencia a relação de herança construcional $\mathrm{CNCv}>\mathrm{CMI}>[(\mathrm{X})[\mathrm{VSN}]]_{\mathrm{FOC}}$. Em termos de sentido, os dados evidenciam a tendência de a construção se configurar como uma instância morfossintática de papel focalizador no PB. Nos exemplos apresentados, vemos a tendência de ocorrência de SNs novos, SNs retomados, eventos de maior grau de saliência e novidade, além do papel coesivo de diferentes elementos gramaticais, como os adverbiais, que parecem refletir a relação básica Tópico-Comentário. Note-se, ainda, a possibilidade de uma construção Cinerg, de SN [+agt], como em (12), emergir com comportamento construcional, em termos de forma e função, previstos por [(X) VSN]FOC, já que seu SN, conforme observável no contexto discursivo, é mais focalizado.

A relação Tópico-Comentário, no âmbito da CTB, aponta a tendência de distribuição da informação em um alinhamento Tópico-Foco. Essa relação é refletida, prototipicamente, na configuração sujeito - predicado, sendo o primeiro um SN SUJ $\mathrm{AGT}_{\mathrm{AT}}$, que tende a ser Tópico, e o segundo o complexo [V SN-AGT], o qual, por sua vez, tende a ser Foco.

Em outras palavras, os elementos componentes da CNC, que também estão presentes na CTB, tendem a fornecer alguma carga informacional nova, modificadora ou mesmo complementar aos elementos que figuram fora do complexo [V $\left.\mathrm{SN}_{-\mathrm{AGT}}\right]_{\mathrm{FOC}}$, tendendo a estarem relacionados à porção discursiva focalizada da cláusula e refletindo o cerne da relação Tópico-Comentário.

Se pensarmos na estrutura informacional básica Tópico-Comentário como o modo default de organização da informação, podemos retomar a discussão sobre herança construcional, alargando-a à discussão sobre informatividade, tão rica às abordagens construcionais.

Assim, na noção de Tópico-Comentário, referida neste trabalho, reconhecemos uma relação, já amplamente apontada na literatura funcionalista (cf.: VALLDUVÍ (1992), DIK (1997)), entre porções discursivas com maior caráter coesivo, anafórico e/ou de retomada, e porções discursivas que têm a propriedade de introduzir informação nova ou de maior grau de saliência discursiva, modificando a proposição anteriormente produzida. $O$ caráter modificador da porção do comentário está diretamente relacionado ao caráter de novidade 


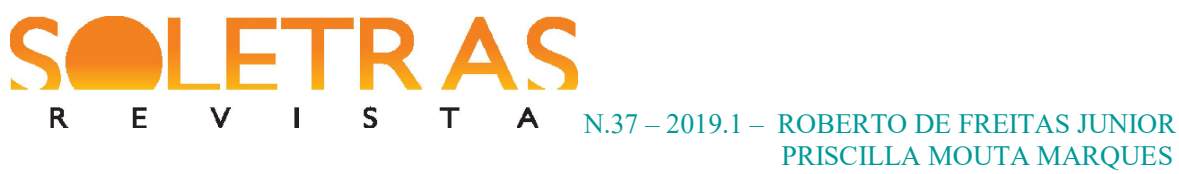

e/ou saliência de sua informação, o que tende a posicioná-lo no papel de Foco do conjunto oracional.

Tal característica discursiva também parece estar presente, ao menos por tendência, na CTB e na CMI, já que - sugerimos - a construção $\mathrm{CNCv}$, por elas herdadas e compartilhadas, apresenta uma configuração sintático-semântica mais propensa a tal caráter informacional, devido à natureza de menor agentividade de seu SN e o posicionamento deste em relação ao verbo.

\section{Considerações Finais}

Neste artigo, buscamos apresentar apontamentos concernentes às relações verificadas entre algumas construções de estrutura argumental - CNC, CTB E CMI, pautando-nos na proposta apresenta por Goldberg (1995) e, principalmente, Diessel (2015) sobre os tipos de links existentes entre os nós (construções) componentes da rede linguística. Atestamos que as três referidas construções compartilham propriedades formais e semânticas/funcionais. Podemos destacar, por exemplo, o fato de todas apresentarem a mesma configuração formal verbo + sintagma nominal com caráter menos agentivo (sendo esta configuração, no que tange a CTB, uma de suas subpartes) - e caracterizam-se pela forte tendência de apresentarem alto grau de novidade e/ou saliência da informação, assumindo, portanto, um papel mais focal.

Embora não tenha sido o foco deste trabalho, a análise aqui desenvolvida permitiu-nos não só depreender os links que unem as construções em questão, mas também destacar que há relações outras estabelecidas entre as instâncias mais ou menos abstratas por elas licenciadas, o que pode vir a ser objeto de trabalhos futuros na área.

\section{Referências}

BARLOW, M.; KEMMER, S. (eds.). Usage based models of language. Stanford, California: CSLI Publications, 2000.

BURZIO, L. Italian Syntax. A government-biding approach. Dordrecht: Reidel Publish Company, 1986. 
BYBEE, J. From usage to grammar: The mind's response to repetition. Language, Washington, DC: Linguistic Society of America, v. 82, n. 4, 2007. p. 711-733.

BYBEE, J. Language, usage and cognition. Cambridge: Cambridge University Press, 2010.

CANÇADO, M. Manual de Semântica: noções básicas e exercícios. Belo Horizonte: Editora UFMG, 2005.

CROFT, W. Radical Construction Grammar: Syntactic Theory in Typological Perspective. Oxford: Oxford University Press, 2001.

DIESSEL, H. (2015). Usage-based construction grammar. In: Dabrowska, E; Divjak, D (Eds.). Handbook of Cognitive Linguistics. Boston: De Gruyter, 2015. p.295-321.

DIK, S. The Theory of Functional Grammar. Berlin/New York: Mouton de Gruyter, 1997.

FREITAS JR., R. Reflexos pragmático-discursivos da L1 na aquisição de inglês como L2: um estudo sobre o uso da cláusula VS. Dissertação de Mestrado. UFRJ: Rio de Janeiro, 2006.

FREITAS JR., R. A constituição discursivo-gramatical da construção (X)VS em inglês como L2: indícios de formação da interlíngua. Tese de Doutorado. Rio de Janeiro: Universidade Federal do Rio de Janeiro, 2011.

GOLBERG, A.E. Constructions: a construction grammar approach to argument structure. Chicago: The University of Chicago Press, 1995.

GOLDBERG, A.E. Constructions at work: the nature of generalization in language. Oxford University Press, 2006.

HOPPER, P.; THOMPSON, S. Transitivity in grammar and discourse. Language, 56(2), p.251-99, 1980.

HUDSON, R. Networks of language: the new Word Grammar. Oxford: Oxford University Press. 2007.

KAY, P.; FILLMORE, C.J. Grammatical constructions and linguistic generalizations: The what's X doing Y construction. Language, 75, p. 1-34, 1999.

MARQUES, P. M. Estudo Diacrônico da Ordenação do Sujeito em Relação ao Verbo no Português. Tese de Doutorado. Rio de Janeiro: Universidade Federal do Rio de Janeiro, 2012.

NARO, A.; VOTRE, S. Discourse Motivations for linguistic regularities - Verb/subject order in spoken Brazilian Portuguese. Probus, 11, p. 73-98, 1999.

PEZATTI, E. Uma abordagem funcionalista da ordem de palavras no português falado. Alfa, São Paulo, 1994. 


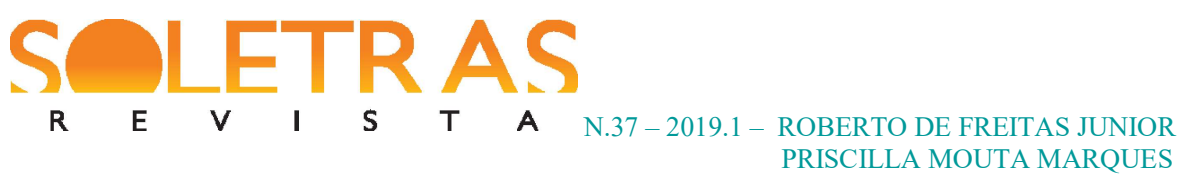

SPANO, M. A ordem V SN em construções monoargumentais na fala culta do português brasileiro e europeu. Dissertação de Mestrado. Rio de Janeiro: Universidade Federal do Rio de Janeiro, 2002.

SPANO, M. A ordem Verbo-Sujeito no Português Brasileiro e Europeu: Um estudo sincrônico da escrita padrão. Tese de Doutorado. Rio de Janeiro: Universidade Federal do Rio de Janeiro, 2008.

STEFANOWITSCH, A. \& GRIES, S. Collostructions: Investigating the interaction of words and constructions. International Journal of Corpus Linguistics 8, p. 209-243, 2003.

VALLDUVÍ, E. The informational component. New York: Garland, 1992.

\title{
On links and constructional inheritance: a review in light of the interrelation between head-complement, basic transitive and unnacusative constructions
}

\begin{abstract}
This article aims to present a brief discussion on the notions of links and constructional inheritance presented in the classic work of Goldberg (1995) and in Diessel's work (2015). Thus, the interconnectivity between three highly schematic constructions in Brazilian Portuguese, the headcomplement, the basic transitive and the unnacusative constructions, is analyzed. To this end, we rely on the theoretical framework of Usage-based Functional Linguistics, according to which language is conceived as a network of constructions: a structured inventory of form-meaning pairings. The analysis points to the sharing of formal and semantic/functional properties by the aforementioned constructions. The three constructions, for example, have the [verb + nominal] phrasal configuration with a [- agent] NP (this configuration being a subpart of the transitive construction) and are likely to present a high degree of novelty and/or informational saliency, therefore assuming a more focal role.
\end{abstract}

Keywords: Constructional network. Links. Argument structure.

Recebido em: 23 de novembro de 2018.

Aceito em: 08 de março de 2019. 